\title{
BIOESTIMULACIÓN Y BIORREMEDIACIÓN DE RECORTES DE PERFORACIÓN CONTAMINADOS CON HIDROCARBUROS
}

\author{
Patricio RIVERA ORTIZ*, Jesús Emmanuel RIVERA LÁRRAGA, \\ Elizabeth del Carmen ANDRADE LIMAS, Lorenzo HEYER RODRÍGUEZ, \\ Francisco Rafael DE LA GARZA REQUENA y Blanca Idalia CASTRO MEZA
}

Universidad Autónoma de Tamaulipas, Facultad de Ingeniería y Ciencias, Centro Universitario Adolfo López Mateos s.n., 87149 Ciudad Victoria, Tamaulipas, México

* Autor para correspondencia: lida@docentes.uat.edu.mx

(Recibido junio 2015; aceptado agosto 2017)

Palabras clave: restauración de suelos, suelos, nitrógeno, fósforo

\section{RESUMEN}

La excavación de pozos para la extracción de gas natural genera grandes cantidades de recortes de perforación contaminados con hidrocarburos. El uso de métodos de biorremediación puede reducir la concentración de hidrocarburos en estos materiales hasta niveles aceptables. Se ensayaron tres suelos del estado de Tamaulipas, México, en mezcla con los recortes contaminados, para conocer su capacidad de inducir la descomposición de hidrocarburos impregnados en los recortes de perforación y lograr la biorremediación de estos últimos. Se evaluó también la bioestimulación de los microorganismos del suelo con $\mathrm{N}$ y $\mathrm{P}$ en la descomposición de los hidrocarburos en dichas mezclas. Las mezclas de suelo y recortes de perforación contaminados con hidrocarburos, procedentes de pozos de extracción de gas natural, se vertieron e incubaron por más de un año en celdas de biorremediación de $1.0 \times 1.2 \times 0.4 \mathrm{~m}$. La proporción suelo:recorte en las mezclas fue de 1:1.5. Se estudiaron dos suelos de uso agrícola y uno de vegetación natural. Con base en el contenido de carbono orgánico de las mezclas, se adicionaron $\mathrm{N}$ y $\mathrm{P}$ (urea y fosfato monoamónico) en cantidades suficientes para inducir en ellas una proporción C:N:P de 100:10:1. El contenido de hidrocarburos disminuyó significativamente cuando los recortes mezclados con suelo se incubaron dentro de las celdas con la adición de N y P, llegando la concentración hasta alrededor de $3000 \mathrm{mg} / \mathrm{kg}$ de hidrocarburos totales, que es el límite máximo permitido en suelos agrícolas por la Norma Oficial Mexicana (NOM-138-SEMARNAT/SSA12012). Plantas de maíz (Zea mays) se desarrollaron en los recortes biorremediados. Los suelos estudiados indujeron la descomposición de los hidrocarburos impregnados en los recortes de perforación y por lo tanto provocaron la biorremediación de los recortes. La bioestimulación de los microorganismos del suelo con nutrientes $\mathrm{N}$ y $\mathrm{P}$, humedad y aireación aumentó la descomposición de los hidrocarburos y propició la biorremediación de los recortes de perforación.

Key words: soils restoration, soils, nitrogen, phosphorus 


\begin{abstract}
The drilling of wells for extracting natural gas generates large quantities of drill cuttings contaminated with hydrocarbons. The use of bioremediation methods can reduce the concentration of hydrocarbons in these materials to an acceptable level. Three soils from the central and north zones of the state of Tamaulipas, Mexico, were assayed by mixing them with drill cuttings contaminated with hydrocarbons to find out the ability of soil to perform the bioremediation of hydrocarbons impregnated in the drill cuttings. The biostimulation of soil microorganisms with $\mathrm{N}$ and $\mathrm{P}$ on the decomposition of hydrocarbons in these mixtures was evaluated. Mixtures of soil and drill cuttings contaminated with hydrocarbons from natural gas extraction wells were poured and incubated in bioremediation cells of $1.0 \times 1.2 \times 0.4 \mathrm{~m}$ for one year. The rate of soil:drill cuttings in these mixtures was 1:1.5. Two agricultural soils and one soil of natural vegetation were studied. Based on the organic carbon content in the mixtures, N and P (urea and monoammonium phosphate) were added, in sufficient amounts to induce a ratio $\mathrm{C}: \mathrm{N}: \mathrm{P}$ of 100:10:1 in the mixture. The hydrocarbons concentration decreased significantly when the drill cuttings, mixed with soil, were incubated in the cells with addition of $\mathrm{N}$ and $\mathrm{P}$, reaching $3000 \mathrm{mg} / \mathrm{kg}$ of total hydrocarbons, which is the maximum limit allowed in the agricultural soils by the official Mexican standard NOM-138-SEMARNAT/ SSA1-2012. Plants of corn (Zea mays) were developed in bioremediated cuttings. The studied soils induced decomposition of hydrocarbons impregnated in drill cuttings and therefore allowed for the bioremediation of cuttings. Biostimulation of soil microorganisms with nutrients $\mathrm{N}$ and $\mathrm{P}$, humidity and aeration increased the decomposition of hydrocarbons and fostered the bioremediation of drill cuttings.
\end{abstract}

\section{INTRODUCCIÓN}

La excavación de pozos para la extracción de gas natural genera grandes cantidades de recortes de perforación del subsuelo contaminados con hidrocarburos (HC) (Méndez-Villegas et al. 2013). Dichos materiales pueden tratarse mediante diversos procesos físicos y químicos para su restauración, pero en la mayoría de los casos esos tratamientos son muy costosos y producen contaminación colateral del ambiente sin que se garantice la eliminación satisfactoria de los HC (Volke-Sepúlveda y Velasco 2002). Éste es un grave problema en la Cuenca de Burgos, en el noreste de México, una zona de explotación de gas natural donde los recortes contaminados extraídos se procesan por medio de tratamientos térmicos ex situ para su restauración y posterior confinamiento en rellenos sanitarios. Sin embargo, los materiales tratados conservan remanentes de $\mathrm{HC}$, lo que a su vez representa una fuente de contaminación para suelos y aguas de la región. Este tratamiento físico tiene además los inconvenientes de consumir elevadas cantidades de combustibles para producir calor y volatilizar los HC (Volke-Sepúlveda y Velasco 2002), así como emitir sustancias dañinas al aire.

Una alternativa de solución es el uso de métodos biológicos de restauración o biorremediación, los cuales se basan en el aprovechamiento de la actividad de microorganismos autóctonos del suelo para llevar a cabo la descomposición de los HC (Adams et al. 2008), a fin de reducir la concentración de los mismos hasta niveles permitidos sin la generación de compuestos nocivos. Para ello es necesario mezclar suelo de la capa superficial con los depósitos de recortes, así como proporcionar a la mezcla condiciones adecuadas para la vida microbiana como aireación, humedad y nutrientes, lo cual se denomina bioestimulación. El aprovechamiento de los microorganismos nativos del suelo representa una alternativa viable para reducir la contaminación de los suelos generada por $\mathrm{HC}$, ya que estos organismos pueden utilizar dichos compuestos como fuente de carbono dando como resultado la descomposición de los mismos (Olguín et al. 2007, Vásquez et al. 2010).

Afortunadamente los microorganismos degradadores de $\mathrm{HC}$ se encuentran en prácticamente cualquier tipo de suelo (Niemi et al. 1987). La restauración de los suelos por medio de la actividad biológica, conocida como biorremediación, se basa en el empleo de organismos vivos como levaduras, bacterias, hongos, microalgas, plantas y sistemas biológicos o enzimas (Pérez-Vargas et al. 2002, Balagurusamy 2005, Peña-Castro et al. 2006, Garbisu et al. 2007, Adams et al. 2008) para mineralizar compuestos tóxicos en condiciones aerobias o anaerobias (Bewley et al. 2001, Velasco y 
Volke-Sepúlveda 2003). La biorremediación se basa en el hecho de que los organismos mencionados tienen la capacidad genética de oxidar y transformar los $\mathrm{HC}$ en productos metabólicos inocuos como $\mathrm{CO}_{2}$ y agua, o biomasa (Benavides et al. 2006). Lo anterior ocurre a través de reacciones bioquímicas de acuerdo con el catabolismo del organismo que le permita la utilización del contaminante como fuente de alimento y energía (Bundy et al. 2002, Velasco y Volke-Sepúlveda 2003). Por tal motivo, esta técnica no genera daños al entorno como sucede cuando se utilizan métodos físicos o químicos (Riojas-González et al. 2010).

En comparación con otras metodologías, la biorremediación es una técnica simple, de fácil aplicación, efectiva y aceptable desde el punto de vista ambiental, presenta riesgos mínimos para la salud humana, animal o vegetal, y además no requiere algún tratamiento posterior (Volke-Sepúlveda y Velasco 2002, Ferrera-Cerrato et al. 2006, RiojasGonzález et al. 2010). Se ha empleado con éxito en la recuperación de suelos y aguas afectados por diversos contaminantes, siendo los $\mathrm{HC}$ con los que se han obtenido mejores resultados (Ferrera-Cerrato et al. 2006). La biorremediación tiene algunas limitantes que dificultan su aplicación, como la disponibilidad de nutrientes esenciales, el alto contenido de arcillas en el suelo que impiden la aireación o disponibilidad de oxígeno, el control de temperatura y humedad, la complejidad del contaminante, la solubilidad del mismo y el tiempo necesario para lograr la descomposición de los residuos orgánicos (Fernández et al. 2006, Ferrera-Cerrato et al. 2006).

La materia orgánica activa —que representa alrededor del 10-20\% de la materia orgánica total del suelo- está constituida por la microbiota edáfica, responsable de los procesos de descomposición de los substratos orgánicos (fracción lábil) y de la síntesis de sustancias que dan origen a otros productos metabólicos como mucílagos, gomas, ácidos, enzimas y polisacáridos extracelulares, y bióxido de carbono (García et al. 2003). La transformación ideal de HC por los microorganismos del suelo es la mineralización, que se basa en que el microorganismo utiliza el contaminante como substrato de crecimiento. Para que el microorganismo pueda crecer a expensas de los $\mathrm{HC}$ deberá disponer de la proporción adecuada de nitrógeno y fósforo en el medio, por lo que será necesario suplementar con fertilizantes los suelos pobres en estos elementos (Atlas y Bartha 2002), lo cual se denomina bioestimulación.

La biorremediación de suelos contaminados con $\mathrm{HC}$ requiere de la aplicación de humedad y nutrientes básicos como nitrógeno y fósforo o bioestimulación a fin de aumentar la actividad de la microbiota nativa e inducir la mineralización de tales compuestos orgánicos. La proporción óptima de C:N:P para llevar a cabo la biorremediación de suelos contaminados con HC es de 100:10:1 (Acuña et al. 2012). La biorremediación es una de las mejores opciones para la descomposición de $\mathrm{HC}$ que han contaminado el suelo (Thompson et al. 2008). En esta investigación se busca demostrar que los suelos tanto agrícolas como de vegetación natural de la región norte del estado de Tamaulipas, donde se lleva a cabo la perforación de pozos para explotación de gas natural, tienen la capacidad de inducir la descomposición de los HC vertidos y mezclados con estos suelos. Asimismo, se pretende medir el efecto de la bioestimulación con nitrógeno y fósforo sobre la descomposición de los $\mathrm{HC}$ en las mezclas de suelo y recortes de perforación contaminados con $\mathrm{HC}$.

El propósito del presente trabajo fue ensayar tratamientos de bioestimulación en recortes de perforación contaminados con $\mathrm{HC}$, tales como la aplicación y el mezclado de suelo de la capa superficial, así como la adición de nutrientes $\mathrm{N}$ y $\mathrm{P}$, con el fin de propiciar la descomposición de los $\mathrm{HC}$ y reducir la concentración de estas sustancias en los recortes hasta un nivel tolerable para el cultivo de maíz (Zea mays) y aceptable por la Norma Oficial Mexicana (NOM) (SEMARNAT 2012). Todo con el objeto de conformar un método de biorremediación para los recortes de perforación contaminados con $\mathrm{HC}$ de la Cuenca de Burgos.

\section{MATERIALES Y MÉTODOS}

El presente estudio se llevó a cabo mediante dos ensayos de campo en los cuales se incubaron mezclas (1:1.5) de suelo de la capa superficial con recortes de perforación contaminados con HC. Las mezclas se colocaron dentro de celdas de biorremediación instaladas sobre la superficie del terreno en condiciones semicontroladas de humedad, aireación y disponibilidad de los nutrientes nitrógeno y fósforo, con la finalidad de inducir y evaluar la bioestimulación de los microorganismos del suelo y la biorremediación de los recortes. El suelo utilizado en las mezclas se tomó de tres sitios ubicados en las zonas centro y norte del estado de Tamaulipas, México, con el propósito de demostrar su capacidad para inducir la descomposición de los HC impregnados en los recortes. Se sembraron plantas de maíz sobre las mezclas para 
observar la respuesta del cultivo a la biorremediación de los recortes inicialmente contaminados.

\section{Descripción de la zona de estudio}

Los recortes de perforación contaminados con $\mathrm{HC}$ que se utilizaron en este estudio se obtuvieron de una planta de tratamiento de residuos peligrosos (RECOTEC, www.gruporeco.com) ubicada en el municipio de Reynosa, Tamaulipas, México. Los recortes transportados hasta la planta RECOTEC se generaron en los pozos de extracción de gas natural ubicados en el norte del estado, región que conforma la Cuenca de Burgos junto con las zonas norte de los estados vecinos de Nuevo León y Coahuila. El suelo utilizado para preparar las mezclas provino de tres sitios: un terreno semidesértico con vegetación natural, localizado junto a la planta de tratamiento de residuos $\left(25^{\circ} 58^{\prime} 30^{\prime \prime} \mathrm{N}, 98^{\circ} 31^{\prime} 12^{\prime}\right.$ " O); y dos suelos agrícolas denominados La Nutria $\left(25^{\circ} 22^{\prime} 30^{\prime \prime} \mathrm{N}, 98^{\circ}\right.$ $13^{\prime} 06^{\prime}$ " O) y La Posta (23 56' 24" N, 99 06' 28” O), ubicados en el km 75 de la carretera San FernandoReynosa en el municipio de Reynosa y en el kilómetro 20 de la carretera Ciudad Victoria-Monterrey en el municipio de Güemes, respectivamente.

\section{Características físicas y químicas de los suelos y recortes de perforación}

Las características de los suelos que se utilizaron en mezcla con los recortes para inducir la biorremediación de estos residuos contaminados con $\mathrm{HC}$ se presentan en el cuadro I. Como se puede observar, los suelos tenían una textura franco-arcillo-arenosa en el sitio de la planta RECOTEC y arcillosa en los sitios de Nutria y Posta. Asimismo, presentaban un $\mathrm{pH}$ medianamente alcalino, bajo contenido de carbono orgánico y concentración baja de sales solubles. Ninguno de los suelos presentaba contaminación con HC. Por el contrario, los recortes de perforación mostraban contenidos elevados de $\mathrm{HC}$ totales así como un alto nivel de sales solubles y un $\mathrm{pH}$ medianamente alcalino (Cuadro II).

\section{Ensayo I. Efecto del suelo y los nutrientes $\mathbf{N}$ y $\mathbf{P}$ en la descomposición de los HC de los recortes de perforación}

Este experimento se llevó a cabo en el sitio Posta, dentro de celdas de biorremediación de $1.0 \times$ $1.2 \times 0.4 \mathrm{~m}$ instaladas sobre la superficie del suelo, cubiertas interiormente con láminas de polietileno negro, tanto en el fondo como en las paredes, a fin de reducir la filtración de los HC. Los recortes y mezclas se incubaron en las celdas durante 13 meses en condiciones semicontroladas de humedad, aireación y disponibilidad de nutrientes $\mathrm{N}$ y $\mathrm{P}$ para inducir y evaluar la bioestimulación de los microorganismos de estos suelos y la biorremediación de los recortes contaminados con HC. Las celdas se construyeron con bloques de cemento y arena de dimensiones 0.40 $\times 0.15$ y $0.20 \mathrm{~m}$ (Fig. 1).

CUADRO I. CARACTERÍSTICAS DE LOS SUELOS UTILIZADOS PARA LA BIORREMEDIACIÓN DE RECORTES CONTAMINADOS CON HIDROCARBUROS

\begin{tabular}{lcccc}
\hline Sitio & Textura & $\begin{array}{c}\mathrm{pH} \\
\text { (relación 1:2) }\end{array}$ & $\begin{array}{c}\text { Conductividad eléctrica } \\
(\mathrm{mS} / \mathrm{cm})\end{array}$ & $\begin{array}{c}\text { Carbono orgánico } \\
\text { total }(\%)\end{array}$ \\
\hline Planta RECOTEC & FAA* & 8.3 & 1.00 & 0.54 \\
La Nutria & Arcilla & 8.0 & 1.21 & 1.39 \\
La Posta & Arcilla & 8.0 & 0.83 & 1.93 \\
Método & Bouyuocos & Potenciometría & Extracto de saturación & Walkley-Black \\
Referencia & Bouyuocos (1962) & Richards (1980) & Richards (1980) & Walkley (1947) \\
\hline
\end{tabular}

RECOTEC: empresa de manejo integral de residuos impregnados con hidrocarburos (www.gruporeco.com)

*FAA: franco arcillosos arenosos

CUADRO II. CARACTERÍSTICAS DE LOS RECORTES DE PERFORACIÓN CONTAMINADOS CON HIDROCARBUROS

\begin{tabular}{lcccc}
\hline Recorte & $\begin{array}{c}\mathrm{pH} \\
(\text { relación 1:2) }\end{array}$ & $\begin{array}{c}\text { Conductividad eléctrica } \\
(\mathrm{mS} / \mathrm{cm})\end{array}$ & $\begin{array}{c}\text { Carbono orgánico } \\
(\%)\end{array}$ & $\begin{array}{c}\text { Hidrocarburos fracción pesada } \\
(\mathrm{mg} / \mathrm{kg})\end{array}$ \\
\hline Ensayo I & 7.8 & 77.6 & 10.0 & 36963.0 \\
Ensayo II & 7.8 & 60.0 & 7.8 & 28902.0 \\
Método & Potenciometría & $\begin{array}{c}\text { Extracto de saturación } \\
\text { Richards (1980) }\end{array}$ & Walkley-Black & Método 9071B \\
Referencia & Richards (1980) & Walkley (1947) & USEPA (1998) \\
\hline
\end{tabular}




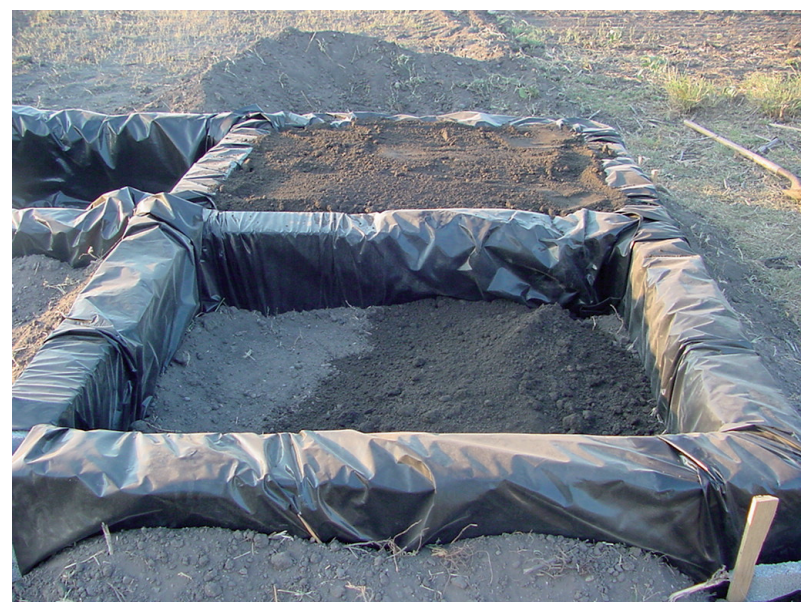

Fig. 1. Ensayo I: celdas de biorremediación de $1.0 \times 1.2 \times 0.4 \mathrm{~m}$ en las que se vertieron e incubaron por 13 meses mezclas de suelo y recortes de perforación, procedentes de pozos de extracción de gas natural

En el cuadro III se presentan los recortes y mezclas incubadas en las celdas durante 13 meses para evaluar la capacidad del suelo agrícola de Posta para inducir la descomposición de $\mathrm{HC}$ impregnados en recortes del subsuelo. Los tratamientos estudiados se describen a continuación. La primera celda se llenó con suelo de la capa superficial $(0-20 \mathrm{~cm})$, que representa el tratamiento testigo. La segunda celda se llenó con recorte impregnado de HC. Luego se añadió suelo sin contaminar en dos celdas más hasta llegar al $40 \%$ del volumen total de cada celda. Posteriormente se rellenó el resto del volumen de ambas celdas con recorte de perforación para conformar

CUADRO III. ENSAYO I: TRATAMIENTOS ESTUDIADOS EN LAS CELDAS DE BIORREMEDIACIÓN PARA MEDIR EL EFECTO DEL SUELO Y DE LOS NUTRIENTES N Y P EN LA DESCOMPOSICIÓN DE LOS HIDROCARBUROS

\begin{tabular}{cl}
\hline $\begin{array}{l}\text { Número de } \\
\text { tratamiento }\end{array}$ & Tratamiento \\
\hline 1 & Suelo agrícola del sitio Posta, tratamiento testigo \\
\hline 2 & $\begin{array}{l}\text { Recortes de perforación contaminados con hi- } \\
\text { drocarburos }\end{array}$ \\
\hline 3 & $\begin{array}{l}\text { Mezcla de recortes de perforación y suelo agrí- } \\
\text { cola Posta }\end{array}$ \\
\hline 4 & $\begin{array}{l}\text { Mezcla de recortes de perforación y suelo agrí- } \\
\text { cola, adicionada con N y P }\end{array}$ \\
\hline
\end{tabular}

el tratamiento de mezclas de suelo y recorte, con y $\sin \mathrm{N}$ y $\mathrm{P}$. El suelo y el recorte se dejaron en reposo sin humedecerse y mezclarse durante 15 días, al término de los cuales se mezcló y homogeneizó el contenido de cada celda. A una de estas dos últimas celdas se le adicionaron $6.941 \mathrm{~kg}$ de urea y $1.746 \mathrm{~kg}$ de fosfato diamónico durante el mezclado a fin de conformar el tratamiento de bioestimulación de la mezcla con $\mathrm{N}$ y P. Se ajustó la relación $\mathrm{C}: \mathrm{N}: \mathrm{P}$ a 100:10:1 en la mezcla, tomando como referencia el contenido de carbono orgánico medido por el método de Walkley-Black (Walkley 1947). La proporción 100:10:1 de C:N:P es óptima para llevar a cabo la biorremediación de suelos contaminados con HC (Acuña et al. 2012).

Una vez colocadas dentro de las celdas, las mezclas se mantuvieron a un nivel mínimo de humedad equivalente al $50 \%$ de la capacidad de campo por un periodo de 13 meses y se removieron una vez por mes dentro de la celda a fin de favorecer la aireación y por lo tanto la descomposición de los HC. Se midió la concentración de HC de fracción pesada de las mezclas (USEPA 1998) al inicio del periodo de incubación y después de seis y 12 meses, para lo cual se tomaron de manera aleatoria tres muestras de un kilogramo de suelo de cada celda y de la capa superficial de $10 \mathrm{~cm}$. Utilizando el mismo tipo de muestreo se midió también la conductividad eléctrica en extracto de saturación (Richards 1980). Se utilizó un diseño completamente aleatorio con cuatro tratamientos (suelo, recorte, suelo-recorte y suelorecorte enriquecidos con $\mathrm{N}$ y $\mathrm{P}$ ) y tres repeticiones. El análisis estadístico consistió en análisis de varianza y prueba de Tukey.

Además de las variables descritas se midieron los porcentajes de germinación y supervivencia, así como la altura de plantas de maíz (Zea mays) para evaluar la respuesta del cultivo establecido en las celdas (40 plantas por celda, alineadas en cuatro hileras). Esto se hizo al término del primero, segundo, tercero, cuarto y decimotercero meses de incubación de las mezclas a fin de comprobar la disminución de la concentración de $\mathrm{HC}$ en los recortes hasta niveles tolerables por las plantas.

\section{Ensayo II. Comparación de tres suelos para indu- cir la biorremediación de recortes de perforación contaminados con hidrocarburos}

Con la finalidad de comparar tres tipos de suelo con relación a su capacidad para inducir la descomposición de $\mathrm{HC}$ en los recortes de perforación, se llevó a cabo un segundo experimento en celdas de iguales dimensiones $(1.0 \times 1.2 \times 0.4 \mathrm{~m})$ 
con mezclas conformadas por recortes de perforación y suelo de cada uno de los sitios estudiados. En el cuadro IV se presentan los tratamientos estudiados en este ensayo. Se colocó suelo agrícola de la capa superficial $(0-20 \mathrm{~cm})$ del sitio Posta en una celda para representar el tratamiento testigo. Una segunda celda se llenó con recortes contaminados. Mezclas (1:1.5) de suelo de cada uno de los tres sitios indicados y recortes contaminados se colocaron también en celdas con la adición de N y P. Se colocó el suelo de cada sitio en la celda hasta llegar a $40 \%$ del volumen total. Después se rellenó el resto del volumen de las tres celdas con recortes de perforación. Estos materiales se dejaron en reposo sin humedecerse durante 15 días, al término de los cuales se mezcló y homogeneizó el contenido de cada celda.

Al igual que en el primer ensayo, durante el mezclado de los materiales se adicionaron urea y fosfato diamónico en las cantidades necesarias para aportar los nutrientes $\mathrm{N}$ y $\mathrm{P}$ a la proporción C:N:P de 100:10:1 (Acuña et al. 2012), tomando como referencia el contenido de carbono orgánico en la mezcla, medido por el método de Walkley-Black (Walkley 1947). La concentración de HC de fracción pesada (USEPA 1998) en las mezclas se midió al inicio y al final de un periodo de incubación de seis meses, para lo cual se tomaron de manera aleatoria tres muestras por celda. Utilizando las mismas muestras se midió también la conductividad eléctrica en extracto de saturación (Richards 1980). El arreglo experimental correspondiente a este ensayo fue el diseño completamente

CUADRO IV. ENSAYO II: TRATAMIENTOS ENSAYADOS PARA COMPARAR TRES SUELOS EN LA BIORREMEDIACIÓN DE RECORTES DE PERFORACIÓN CONTAMINADOS CON HIDROCARBUROS

\begin{tabular}{cl}
\hline $\begin{array}{l}\text { Número de } \\
\text { tratamiento }\end{array}$ & Tratamiento \\
\hline 1 & Suelo Posta, tratamiento testigo \\
\hline 2 & $\begin{array}{l}\text { Recortes de perforación contaminados con hi- } \\
\text { drocarburos }\end{array}$ \\
\hline 3 & Mezcla de suelo Posta y recortes \\
\hline 4 & $\begin{array}{l}\text { Mezcla de suelo planta RECOTEC y recortes, } \\
\text { con N y P }\end{array}$ \\
\hline 5 & Mezcla de suelo Nutria y recortes, con N y P \\
\hline 6 & Mezcla de suelo Posta y recortes, con N y P \\
\hline
\end{tabular}

aleatorio con seis tratamientos y tres repeticiones. El análisis estadístico consistió en análisis de varianza y prueba de Tukey.

En este ensayo también se evaluó la respuesta del cultivo de maíz (Zea mays) variedad criollo regional, establecido en las celdas al término del sexto mes de incubación de las mezclas, a fin de determinar por medio de su altura si la biorremediación se llevó a cabo en los recortes y saber si la concentración de $\mathrm{HC}$ en los recortes disminuyó hasta niveles tolerables por las plantas. Para conocer el efecto de los $\mathrm{HC}$ en la germinación se sembraron semillas $100 \%$ viables de maíz al término del sexto mes, en una población de 40 plantas por celda, distribuidas en cuatro hileras. Se midió el porcentaje de germinación del maíz, el porcentaje de supervivencia de los germinados y el crecimiento de las plantas en centímetros. El análisis de varianza y la prueba de comparación de medias se realizaron a través de la estadística Ji cuadrada $\left(\mathrm{X}^{2}\right)$ para los porcentajes de germinación y supervivencia.

\section{RESULTADOS Y DISCUSIÓN}

Ensayo I. Efecto del suelo y los nutrientes $\mathbf{N}$ y $P$ en la descomposición de hidrocarburos en los recortes de perforación

Contenido de hidrocarburos y tiempo de incubación

En la figura 2 se muestra el contenido de $\mathrm{HC}$ en los recortes de perforación y en mezclas de estos materiales con suelo agrícola, tanto al inicio como después de seis y 12 meses de incubación, dentro de las celdas de biorremediación. Como se puede observar, el contenido inicial de $\mathrm{HC}$ en los recortes de perforación fue de casi $37000 \mathrm{mg} / \mathrm{kg}$ mientras que la mezcla de recortes y suelo contenía $25000 \mathrm{mg} / \mathrm{kg}$. Después de seis meses de incubación de los materiales el contenido de hidrocarburos disminuyó significativamente en todas las celdas. Aunque en los recortes de perforación incubados sin suelo se redujo el contenido de hidrocarburos debido al efecto de volatilización o atenuación natural, la disminución de la concentración de hidrocarburos en los recortes fue mayor cuando éstos se incubaron en mezcla con el suelo. Lo anterior significa que la pérdida de hidrocarburos en las mezclas se debió a la actividad de descomposición de los microorganismos autóctonos del suelo (Olguín et al. 2007, Vásquez et al. 2010). Sin embargo, la disminución de estas sustancias en las mezclas sin adición de nutrientes no llegó al nivel establecido por la NOM-138-SEMARNAT/SSA1-2012 

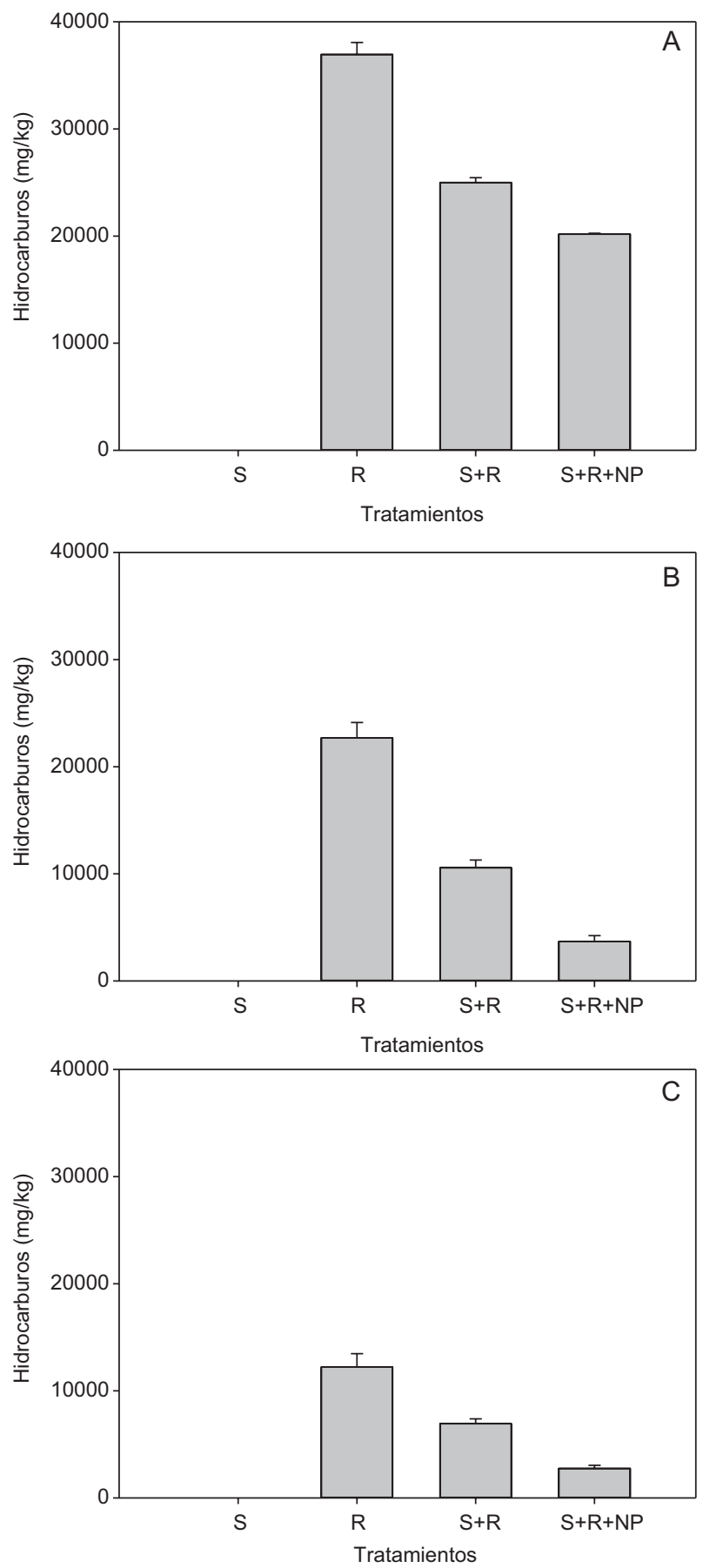

Fig. 2. Ensayo I: contenido de hidrocarburos en suelo (S), recortes de perforación (R), mezcla de ambos materiales $(\mathrm{S}+\mathrm{R})$ y mezcla con $\mathrm{N}$ y $\mathrm{P}(\mathrm{S}+\mathrm{R}+\mathrm{NP})$ incubados en celdas durante 0 (A), 6 (B) y 12 (C) meses $(\mathrm{n}=36, \mathrm{p}<$ $0.05)$

(SEMARNAT 2012), que es de $3000 \mathrm{mg} \mathrm{HC} / \mathrm{kg}$ para suelos agrícolas, ya que el contenido de hidrocarburos se redujo sólo hasta $10563 \mathrm{mg} \mathrm{HC} / \mathrm{kg}$ en este primer periodo. Un nivel cercano a los $3000 \mathrm{mg} \mathrm{HC/}$ $\mathrm{kg}$ se alcanzó en la mezcla enriquecida con $\mathrm{N}$ y $\mathrm{P}$ al término de seis meses de incubación (3586 mg/kg). Esto indica que la actividad de los microrganismos que descomponen los hidrocarburos se incrementó con la adición de nutrientes, ya que al ser éstos elementos limitantes de la producción de biomasa los habrían estimulado para aumentar la tasa de descomposición de hidrocarburos (Acuña et al. 2012). Después de 12 meses de incubación, el nivel de hidrocarburos en los recortes adicionados con $\mathrm{N}$ y $\mathrm{P}$ descendió hasta $2700 \mathrm{mg} \mathrm{HC} / \mathrm{kg}$. Por otro lado, en la mezcla de recortes en que no se agregaron los nutrientes el contenido de hidrocarburos fue de $6928 \mathrm{mg}$ $\mathrm{HC} / \mathrm{kg}$, más del doble de los $3000 \mathrm{mg} \mathrm{HC} / \mathrm{kg}$ que indica la NOM.

La disminución de los hidrocarburos hasta niveles cercanos a los aceptables, debido al proceso de biorremediación de los recortes, ocurrió durante los primeros seis meses en las mezclas adicionadas con los nutrientes $\mathrm{N}$ y P. En las mezclas donde no se adicionaron los nutrientes, ese nivel no se alcanzó a pesar de haber permanecido en incubación por un periodo de 12 meses. Debido a que en la segunda mitad del periodo anual de incubación la tasa de descomposición de hidrocarburos fue muy baja en comparación con los primeros seis meses, se puede decir que la biorremediación de recortes de perforación contaminados con hidrocarburos se puede lograr en un periodo ligeramente mayor al medio año si se aplican condiciones adecuadas de humedad, aireación y disponibilidad de $\mathrm{N}$ y $\mathrm{P}$.

\section{Conductividad eléctrica y tiempo de incubación de los recortes de perforación}

Como se mencionó en la descripción de los recortes de perforación (Cuadro II), una de las características principales de estos materiales del subsuelo es su alto contenido de sales, mayormente de $\mathrm{Ca}$ y $\mathrm{Mg}$, ya que se encontró en ellos una conductividad eléctrica (CE) de más de $77 \mathrm{dS} / \mathrm{m}$ medida en extracto de saturación. Esta elevada conductividad eléctrica se observó también en las mezclas de suelo y recortes al inicio del periodo de incubación, en las que se observaron valores de 36 y $40 \mathrm{dS} / \mathrm{m}$, respectivamente (Fig. 3). Después de tres meses de que los recortes y las mezclas se colocaron en las celdas, el nivel de $\mathrm{CE}$ descendió en todas las mezclas hasta niveles tolerables para los cultivos comunes (Richards 1980) y por lo tanto por los microrganismos del suelo: menos de $4 \mathrm{dS} / \mathrm{m}$.

El descenso del nivel de salinidad se debió a la abundante precipitación pluvial ocurrida a partir de 


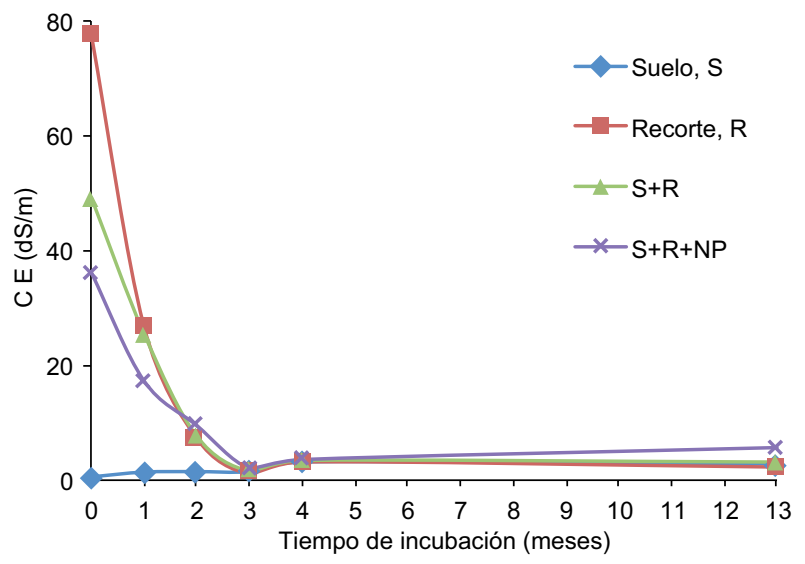

Fig. 3. Ensayo I: conductividad eléctrica (CE) en sustratos de suelo $(\mathrm{S})$, recortes de perforación (R), mezcla de ambos materiales $(\mathrm{S}+\mathrm{R})$ y mezcla con $\mathrm{N}$ y $\mathrm{P}(\mathrm{S}+\mathrm{R}+\mathrm{NP})$ incubados en celdas durante 13 meses

la segunda semana posterior a la instalación del experimento y de manera intermitente durante los primeros tres meses del periodo experimental (CONAGUA 2009), lo que provocó la lixiviación de las sales solubles y la disminución de la CE en las mezclas de recortes y suelo contenidas en las celdas (Fig. 4). El proceso de lixiviación no afectó de manera importante a los hidrocarburos, ya que éstos permanecieron en alta concentración en el suelo como los muestran las figuras 2 y 8 .

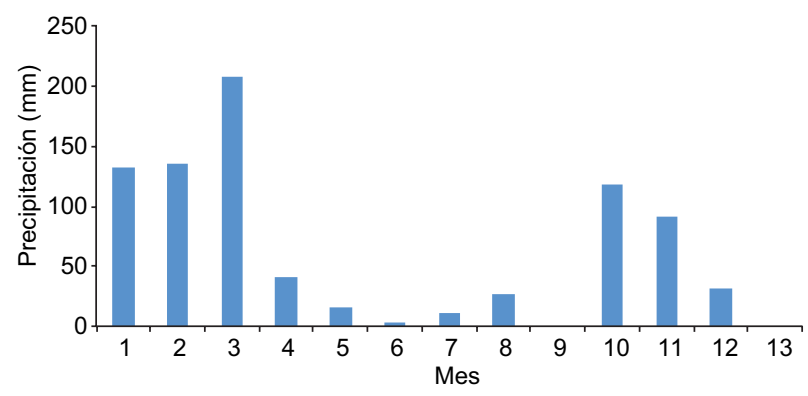

Fig. 4. Precipitación pluvial mensual ocurrida en el sitio Posta y periodo experimental (CONAGUA 2009)

\section{Emergencia, supervivencia y crecimiento de plantas de maíz.}

La figura 5 muestra los porcentajes de emergencia de plántulas de maíz sembradas en los recortes de perforación y en sus mezclas con suelo agrícola. Como se puede observar, las plántulas de maíz no emergieron en el recorte contaminado ni en las mezclas de recortes y suelo agrícola después del primer mes de incubación debido a la elevada concentración

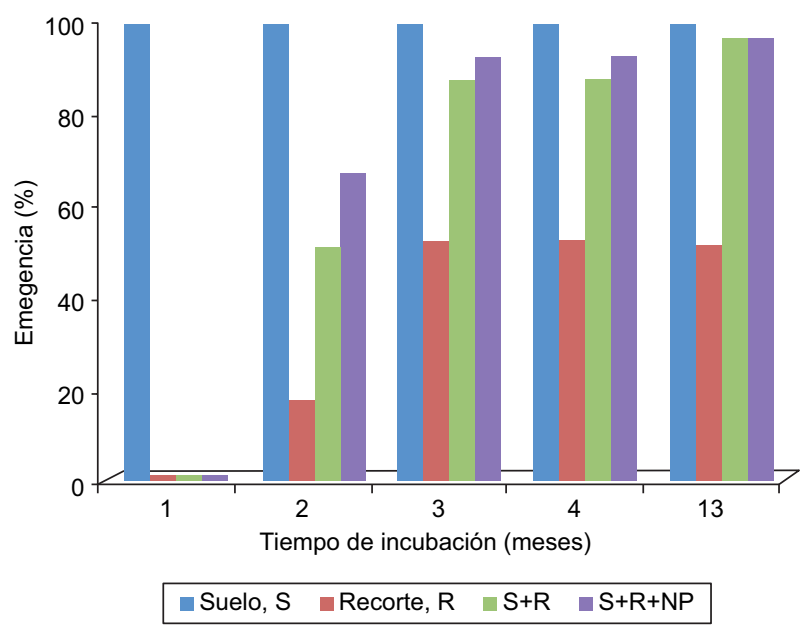

Fig. 5. Ensayo I: emergencia de plántulas de maíz sembradas en sustratos de suelo (S), recortes de perforación (R), mezcla de ambos materiales $(\mathrm{S}+\mathrm{R})$ y mezcla con $\mathrm{N}$ y $\mathrm{P}(\mathrm{S}+\mathrm{R}+\mathrm{NP})$ incubados en celdas durante 13 meses

de hidrocarburos (Rivera-Cruz y Trujillo-Narcia 2004) y sales solubles (Figs. 2 y 3). Al término de los dos primeros meses de incubación se observó emergencia, pero en porcentajes muy bajos: menos de $20 \%$ en las celdas con recortes contaminados, $50 \%$ en las celdas con mezcla de recortes y suelo, y más de $60 \%$ en la misma mezcla pero adicionada con N y P. Después de tres meses de incubación, tiempo en que la CE había disminuido a menos de $2.1 \mathrm{dS} / \mathrm{m}$ en todas las celdas debido a la abundante precipitación (Fig. 4) y lixiviación de sales solubles, la emergencia continuó al $50 \%$ en el recorte de perforación y al $80 \%$ en las mezclas de recorte y suelo agrícola. Esta tendencia indica que después del tercer mes de incubación, la concentración de sales solubles en las mezclas (y quizás el contenido de hidrocarburos) había disminuido a niveles lo suficientemente bajos para permitir la emergencia de las plántulas de maíz (Richards 1980).

Después de cuatro meses de incubación, la emergencia y supervivencia del cultivo se mantuvieron en los mismos porcentajes. Al cumplirse 13 meses de incubación la CE se mantuvo baja (alrededor de 4 $\mathrm{dS} / \mathrm{m}$ ), aproximadamente en los mismos valores observados en las materiales desde el tercer mes (Fig. 3). Después de más de un año, la concentración de hidrocarburos se mantuvo alta, entre 6000 y $12000 \mathrm{mg} / \mathrm{kg}$ en la celda llena con recortes y en las mezclas sin bioestimulación con nutrientes, por lo que las plantas murieron. Por el contrario, el contenido de hidrocarburos se redujo en las mezclas que habían sido enriquecidas con los nutrientes $\mathrm{N}$ y $\mathrm{P}$, por lo que 
la supervivencia de las plantas de maíz llegó a un $90 \%$. Estos resultados indican que la remoción de hidrocarburos fue más eficiente cuando los recortes se incubaron mezclados con suelo y se enriquecieron con nutrientes N y P (Atlas y Bartha 2002). Por lo anterior se asume que la bioestimulación de las mezclas con base en humectación, aireación y suministro de nutrientes $\mathrm{N}$ y $\mathrm{P}$, provocó una reducción significativa en la concentración de hidrocarburos en los recortes de perforación desde los primeros seis meses de incubación, principalmente en la mezcla adicionada con $\mathrm{N}$ y $\mathrm{P}$.

Respecto a la supervivencia y crecimiento del cultivo, después de más de un año de biorremediación de los recortes contaminados con hidrocarburos, tiempo en que la $\mathrm{CE}$ en todas las celdas se mantuvo en valores tolerables para el cultivo (Richards 1980), las plantas de maíz sobrevivieron (Fig. 6) y

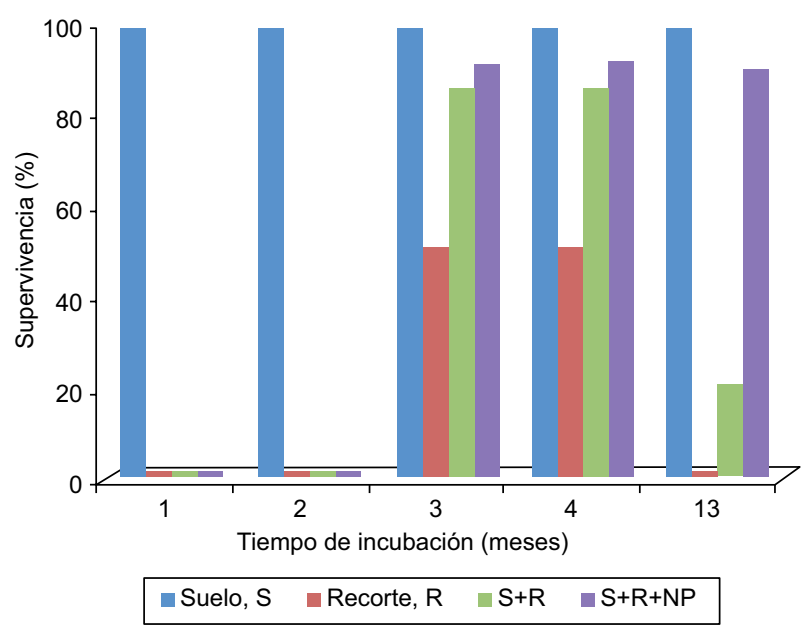

Fig. 6. Ensayo I: supervivencia de plantas de maíz de 30 días de edad, sembradas en sustratos de suelo (S), recortes de perforación $(\mathrm{R})$, mezcla de ambos materiales $(\mathrm{S}+\mathrm{R})$ y mezcla con $\mathrm{N}$ y $\mathrm{P}(\mathrm{S}+\mathrm{R}+\mathrm{NP})$ incubados en celdas durante 13 meses crecieron considerablemente en la mezcla de recortes y suelo adicionada con $\mathrm{N}$ y $\mathrm{P}(85 \mathrm{~cm})$, aunque no con el mismo vigor que las plantas sembradas en suelo libre de hidrocarburos (testigo), donde se registró una altura de $155 \mathrm{~cm}$.

Por el contrario, a pesar del largo tiempo de incubación de los recortes y de la mezcla recortes-suelo $\sin \mathrm{N}$ y $\mathrm{P}$, las plantas de maíz no sobrevivieron o su crecimiento fue raquítico en estos materiales, debido a la persistencia de los hidrocarburos en la mezcla (Rivera-Cruz y Trujillo-Narcia 2004) aun después de 13 meses de incubación (Cuadro V). Lo anterior significa que la biorremediación es más rápida cuando se agregan los nutrimentos limitantes $\mathrm{N}$ y $\mathrm{P}$ al suelo y que la bioestimulación con estos nutrientes es indispensable para lograr la biorremediación de dichos materiales contaminados (Atlas y Bartha 2002) como se muestra en la figura 7.

\section{Ensayo II. Comparación de tres suelos en la biorremediación de recortes de perforación con- taminados con hidrocarburos Contenido de hidrocarburos}

La figura 8 muestra el contenido de hidrocarburos en mezclas de recortes de perforación con suelo de tres sitios, incubadas en celdas de biorremediación durante seis meses y adicionadas con nutrientes $\mathrm{N}$ y $\mathrm{P}$. Como se puede observar, al inicio del periodo el contenido de hidrocarburos en las mezclas era de 11000 a $14000 \mathrm{mg} / \mathrm{kg}$, y después de seis meses de incubación el contenido de estos contaminantes descendió significativamente en las tres mezclas hasta valores tolerables por el cultivo de maíz (entre 2000 y $4500 \mathrm{mg} / \mathrm{kg}$ ). Los menores contenidos de hidrocarburos se lograron en las mezclas de recortes con los suelos Nutria y planta RECOTEC como resultado de los seis meses de incubación. A pesar de que en las mezclas de recortes con el suelo Posta el contenido de hidrocarburos $(4500 \mathrm{mg} / \mathrm{kg})$ permaneció por arriba de $3000 \mathrm{mg} / \mathrm{kg}$,

CUADRO V. ENSAYO I: DESARROLLO DE PLANTAS DE MAÍZ DE 37 DÍAS DE EDAD SEMBRADAS EN CELDAS DE BIORREMEDIACIÓN RELLENAS CON SUELO AGRÍCOLA, RECORTES DE PERFORACIÓN Y MEZCLAS DE AMBOS MATERIALES CON Y SIN N Y P, DESPUÉS DE 13 MESES DE INCUBACIÓN

\begin{tabular}{|c|c|c|c|c|}
\hline $\begin{array}{l}\text { Número de } \\
\text { tratamiento }\end{array}$ & Tratamiento & $\begin{array}{c}\text { Emergencia } \\
(\%)\end{array}$ & $\begin{array}{c}\text { Supervivencia } \\
(\%)\end{array}$ & $\begin{array}{c}\text { Altura } \\
\text { promedio }(\mathrm{cm})\end{array}$ \\
\hline 1 & Suelo agrícola & $100^{\mathrm{a}}$ & $100^{\mathrm{a}}$ & $155^{\mathrm{a}}$ \\
\hline 2 & Recortes de perforación & $50^{\mathrm{b}}$ & $0^{\mathrm{c}}$ & $0^{\mathrm{d}}$ \\
\hline 3 & Mezcla de recortes de perforación y suelo agrícola & $95^{\mathrm{a}}$ & $20^{\mathrm{b}}$ & $22^{\mathrm{c}}$ \\
\hline 4 & Mezcla de recortes de perforación y suelo agrícola, adicionada con $\mathrm{N}$ y $\mathrm{P}$ & $95^{\mathrm{a}}$ & $90^{\mathrm{a}}$ & $85^{\mathrm{b}}$ \\
\hline
\end{tabular}

Valores con letras distintas muestran diferencias significativas (germinación y supervivencia $X^{2}, p<0.05$; altura Tukey, $\mathrm{p}<0.05, \mathrm{n}=12$ ) 

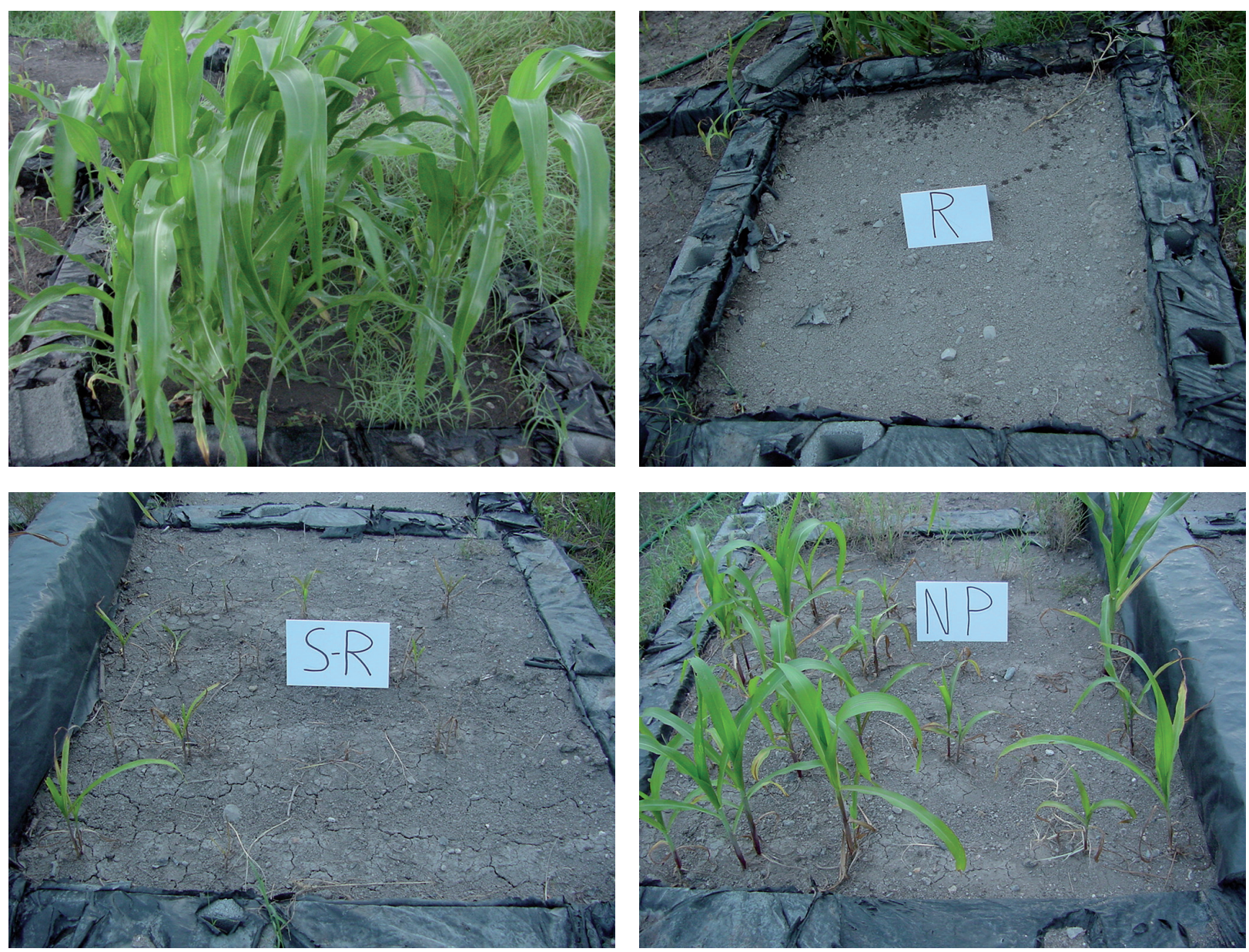

Fig. 7. Ensayo I: plantas de maíz de 50 días de edad sembradas en celdas rellenas con suelo agrícola, recortes de perforación (R), mezcla de ambos materiales $(\mathrm{S}+\mathrm{R})$ y mezcla de estos materiales con la adición de $\mathrm{N}$ y $\mathrm{P}(\mathrm{NP})$, después de 13 meses de incubación
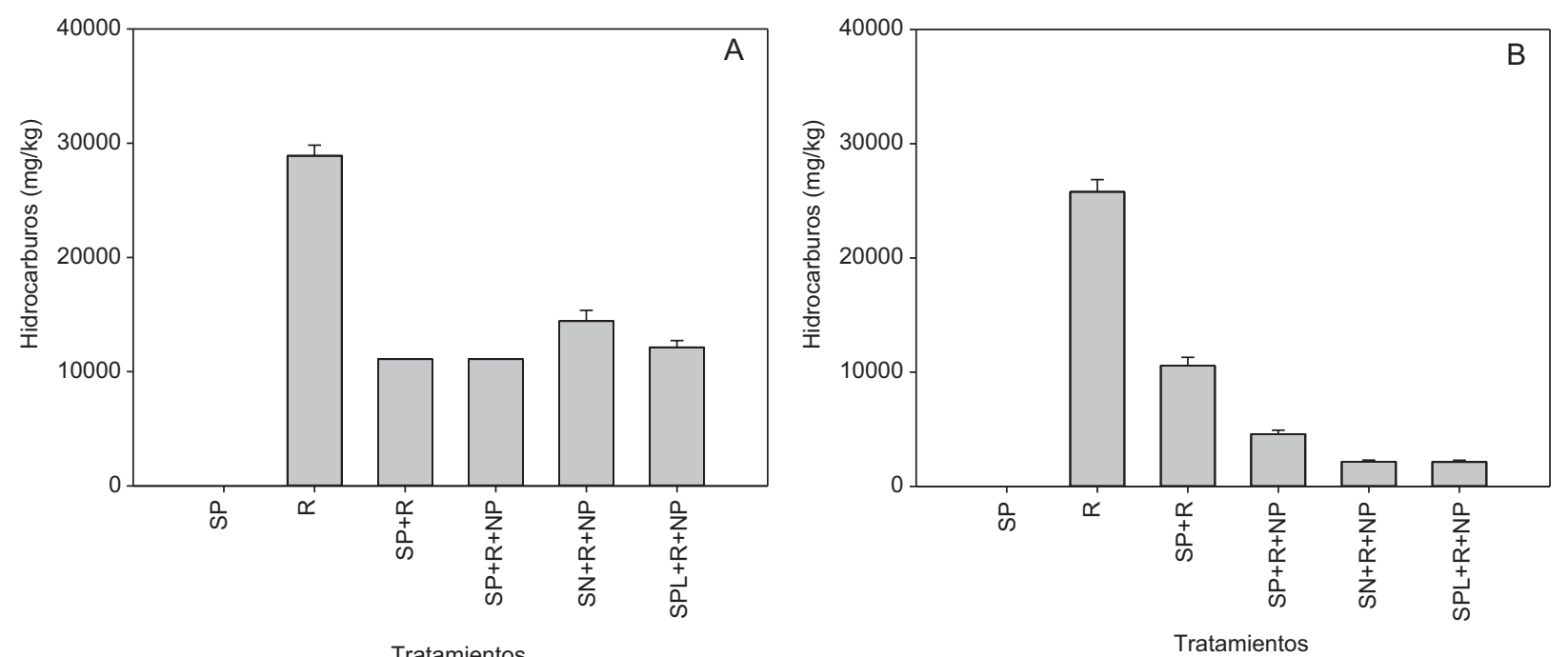

Fig. 8. Ensayo II: contenido de hidrocarburos en el suelo Posta (SP), recortes (R), mezcla del suelo Posta con recortes (SP $+\mathrm{R})$ y mezclas del recorte con los suelos Posta $(\mathrm{SP}+\mathrm{R}+\mathrm{NP})$, Nutria $(\mathrm{SN}+\mathrm{R}+\mathrm{NP})$ y planta RECOTEC $(\mathrm{SPL}+\mathrm{R}+\mathrm{NP})$, adicionadas con $\mathrm{N}$ y $\mathrm{P}$ e incubadas en celdas durante 0 (A) y 6 (B) meses $(n=36, \mathrm{p}<0.05)$ 
las plantas de maíz tuvieron un crecimiento similar al de aquellas que crecieron en las mezclas Nutria y planta RECOTEC (Fig. 8), lo cual significa que las plantas de maíz toleran la presencia de hidrocarburos en un concentración de hasta $4500 \mathrm{mg} / \mathrm{kg}$. Sin embargo, en un periodo mayor (12 meses), el nivel de hidrocarburos descendió a $2746 \mathrm{mg} / \mathrm{kg}$ (valor menor que el establecido por la NOM, de $3000 \mathrm{mg} /$ $\mathrm{kg}$ [SEMARNAT 2012]) en las mezclas de recortes con el suelo Posta.

\section{Emergencia, supervivencia y crecimiento del cultivo de maíz}

En el cuadro VI se presentan los datos de emergencia, supervivencia y crecimiento del cultivo de maíz sembrado en mezclas de recortes contaminados y suelo de los sitios planta RECOTEC, Nutria y Posta después de seis meses de incubación de las mezclas en condiciones de bioestimulación con humedad, nutrientes N y P, y aireación. Como se puede observar, las plántulas de maíz emergieron al $100 \%$ en el suelo sin contaminar y en las mezclas de recortes con suelo de los tres sitios, lo cual confirma que la biorremediación de los recortes contaminados con hidrocarburos se llevó a cabo durante los seis meses de incubación de las mezclas en celdas con condiciones controladas. La emergencia se redujo a la mitad cuando las mezclas se incubaron sin la adición de $\mathrm{N}$ y $\mathrm{P}$, lo cual indica que la descomposición de hidrocarburos no se efectuó de manera satisfactoria debido a que los microorganismos del suelo no tuvieron los nutrientes esenciales para realizar el proceso (Acuña et al. 2012). Se deduce por lo tanto que si estos nutrientes no se adicionan a las mezclas de suelo y recortes la biorremediación es muy lenta (Atlas y Bartha 2002). La figura 9 muestra que la misma tendencia se observó en el crecimiento de las plantas después de 37 días de haber sido sembradas sobre recortes biorremediados. Esta figura demuestra que el nivel de hidrocarburos disminuyó en los recortes hasta niveles tolerables por el cultivo de maíz, después de someter por seis meses estos residuos a la bioestimulación y que la biorremediación inducida en los recortes contaminados con hidrocarburos fue efectiva.

Estos resultados indican que los tres suelos estudiados contienen los microoganismos necesarios para llevar a cabo la descomposición de los hidrocarburos contenidos en las recortes de perforación y que los tres suelos pueden utilizarse para inducir la biorremediación de recortes contaminados con hidrocarburos, siempre y cuando se realice la bioestimulación de los microorganismos del suelo manteniendo condiciones satisfactorias de humedad, aireación y disponibilidad de nutrientes $\mathrm{N}$ y P. Lo anterior indica, además, de acuerdo con Niemi et al. (1987) que todos los suelos del centro y norte del estado de Tamaulipas pueden dar buenos resultados en la biorremediación de recortes de perforación contaminados con hidrocarburos.

\section{CONCLUSIONES}

La bioestimulación con nutrientes $\mathrm{N}$ y $\mathrm{P}$, humedad y aireación de los microorganismos de tres suelos del estado de Tamaulipas previamente mezclados e incubados con recortes de perforación de pozos para la extracción de gas natural, en proporción suelo:recortes de 1:1.5, aumentó la descomposición de los hidrocarburos impregnados en los recortes e indujo la biorremediación de estos materiales contaminados.

CUADRO VI. ENSAYO II: EMERGENCIA, SUPERVIVENCIA Y ALTURA DE PLANTAS DE MAÍZ SEMBRADAS EN CELDAS DE BIORREMEDIACIÓN RELLENAS CON SUELO AGRÍCOLA, RECORTES DE PERFORACIÓN Y MEZCLAS DE AMBOS MATERIALES, DESPUÉS DE SEIS MESES DE INCUBACIÓN

\begin{tabular}{|c|c|c|c|c|}
\hline $\begin{array}{l}\text { Número de } \\
\text { tratamiento }\end{array}$ & Tratamiento & $\begin{array}{c}\text { Emergencia } \\
(\%)\end{array}$ & $\begin{array}{c}\text { Supervivencia a } \\
37 \text { días de edad }(\%)\end{array}$ & $\begin{array}{c}\text { Altura a } 37 \text { días } \\
\text { de edad }(\mathrm{cm})\end{array}$ \\
\hline 1 & Suelo Posta & $100^{\mathrm{a}}$ & $100^{\mathrm{a}}$ & $56.7^{\mathrm{a}}$ \\
\hline 2 & Recorte & $0^{\mathrm{c}}$ & $0^{\mathrm{c}}$ & $0^{\mathrm{d}}$ \\
\hline 3 & Mezcla de suelo Posta y recorte & $50^{\mathrm{b}}$ & $20^{\mathrm{b}}$ & $12.3^{\mathrm{c}}$ \\
\hline 4 & Mezcla de suelo planta RECOTEC y recorte, con N y P & $100^{\mathrm{a}}$ & $100^{\mathrm{a}}$ & $28.3^{\mathrm{b}}$ \\
\hline 5 & Mezcla de suelo Nutria y recorte, con N y P & $100^{\mathrm{a}}$ & $100^{\mathrm{a}}$ & $30.0^{\mathrm{b}}$ \\
\hline 6 & Mezcla de suelo Posta y recorte, con N y P & $100^{\mathrm{a}}$ & $100^{\mathrm{a}}$ & $30.0^{\mathrm{b}}$ \\
\hline
\end{tabular}

Valores con letras distintas muestran diferencias significativas (germinación y supervivencia $\mathrm{X}^{2}, \mathrm{p}<0.05$; altura Tukey, $\mathrm{p}<$ $0.05, \mathrm{n}=18)$ 

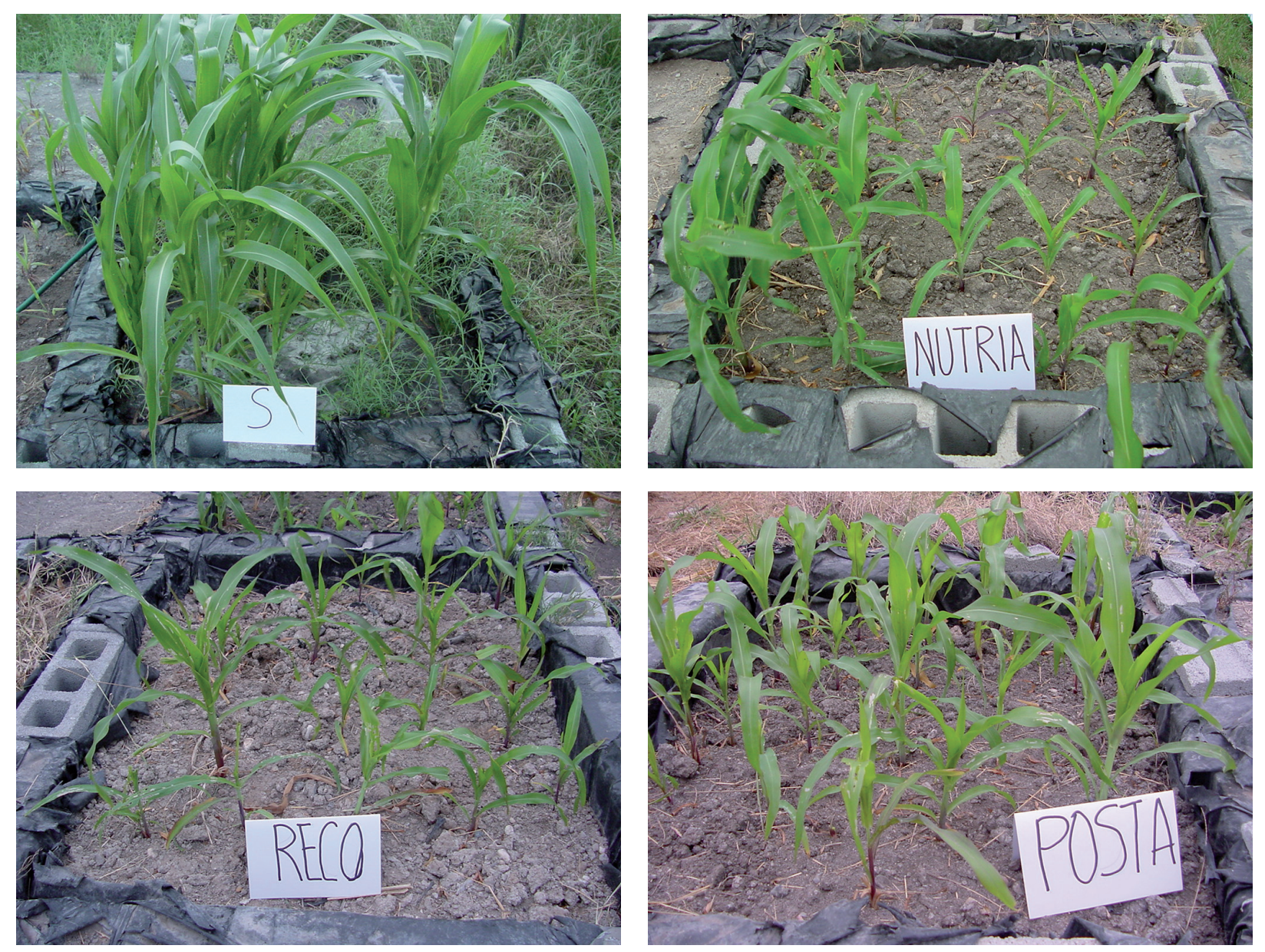

Fig. 9. Ensayo II: plantas de maíz de 37 días de edad sembradas después de seis meses de biorremediación en suelo (S, testigo), y mezclas de los recortes con los suelos Nutria, planta RECOTEC (RECO) y Posta, adicionadas con N y P

Los resultados de esta investigación se pueden aplicar a gran escala en la biorremediación de recortes contaminados extraídos de la perforación de pozos en la Cuenca de Burgos.

\section{AGRADECIMIENTOS}

Al Fondo Mixto de Fomento a la Investigación Científica y Tecnológica, Consejo Nacional de Ciencia y Tecnología-Gobierno del Estado de Tamaulipas, por el financiamiento brindado para realizar esta investigación.

A la empresa RECOTEC S.A. de C.V. de Ciudad Reynosa, Tamaulipas, México, especializada en el manejo integral de residuos impregnados con hidrocarburos, por su apoyo para llevar a cabo este proyecto.

\section{REFERENCIAS}

Acuña A.J., Tonín N.L., Diaz V., Pucci G.N. y Pucci O.H. (2012). Optimización de un sistema de biorremediación de hidrocarburos a escala de laboratorio. Ing. Invest. y Tecnol. 13 (1), 105-112.

Adams R.H., Zavala-Cruz J. y Morales-García F. (2008). Concentración residual de hidrocarburos en el suelo del trópico II: afectación a la fertilidad y su recuperación. Interciencia 33 (7), 483-489.

Atlas R.M. y Bartha R. (2002). Ecología microbiana y microbiología ambiental. $6^{\text {a }}$ ed. Editorial Pearson, Madrid, España, 677 pp.

Balagurusamy N. (2005). Anaerobic bioremediation, an untapped potential. Rev. Mex. Ing. Quím. 4 (3), 273-287.

Benavides J., Quintero G., Guevara-Vizcaíno A.L., JaimesCáceres D.C., Gutiérrez-Riaño S.M. y Miranda-García J. 
(2006). Biorremediación de suelos contaminados con hidrocarburos derivados del petróleo. NOVA 4 (5), 1-116.

Bewley R., Alexander J.G. y Webb G.H. (2001). Ex situ and in situ bioremediation of former oil distribution. Land Contamination \& Reclamation 9, 1-15.

Bouyoucos G. (1962). Hydrometer method improved for making particle size analysis of soils. Agron. J. 54, 464-465.

DOI: 10.2134/agronj1962.00021962005400050028x

Bundy G., Paten G.I. y Campbell C.D. (2002). Microbial communities in different soil types do not converge after diesel contamination. J. Appl. Microbiol. 92 (2), 276-288.

DOI: $10.1046 /$ j.1365-2672.2002.01528.x

CONAGUA (2009). Base de datos de precipitación pluvial. Comisión Nacional del Agua, Gerencia Regional Golfo Centro, delegación estatal Tamaulipas. Ciudad Victoria, Tamaulipas, México.

Fernández C., Silva M., Pereira J.C., Mallia A., Llobregat M.J. y Altomare V. (2006). Biodegradabilidad de las fracciones de resinas y asfaltenos por pseudomonas en suelo impactado con crudo mediano. Ingeniería U.C. 13 (2), 7-13.

Ferrera-Cerrato R., Rojas-Avelizapa N.G., Poggi-Varaldo H.M., Alarcón A.A. y Cázares-Villanueva R. O. (2006). Procesos de biorremediación de suelo y agua contaminados por hidrocarburos del petróleo y otros compuestos orgánicos. Rev. Latinoam. Microbiol. 48 (2), 179-187.

Garbisu C., Becerril J.M., Epelde L. y Alkorta I. (2007). Bioindicadores de la calidad del suelo: herramienta metodológica para la evaluación de la eficacia de un proceso fitorremediador. Ecosistemas 16 (2), 1-6.

García I.C., Gil F., Hernández T. y Muñoz M. (2003). Medida de actividades enzimáticas y biomasa microbiana. En: Técnicas de análisis de parámetros bioquímicos en suelos (García C.I., Gil F., Hernández T. y Trasar C., Eds.). Mundi-Prensa, Madrid, España, 562 pp.

Méndez-Villegas R., Gómez-Rivera P., Ledesma-Herrera J.I. y Ceniceros-González C. (2013). Manejo integral de los recortes de perforación de la industria petrolera en Tabasco. Revista Iberoamericana de las Ciencias Biológicas y Agropecuarias 2 (4), 1-20.

DOI: $10.23913 /$ ciba.v2i4.22

Niemi G.J., Veith G.D., Regal R.R. y Vaishnav D.D. (1987). Structural features associated with degradable and persistent chemicals. Environ. Toxicol. Chem. 6 (7), 515-527.

DOI: $10.1002 /$ etc. 5620060704

Olguín E.J., Sánchez-Galván G. y Pérez-Pérez T. (2007). Assessment of the phytoremediation potential of Salvinia minima baker compared to Spirodela polyrrhiza in high-strength organic wastewater. Water Air Soil Poll. 181 (1-4), 135-147.

DOI: $10.1007 / \mathrm{s} 11270-006-9285-9$

Peña-Castro J.M., Barrera-Figueroa B.E., Ruiz-Medrano R. y Xoconostle-Cázares B. (2006). Bases moleculares de la fitorremediación de hidrocarburos totales del petróleo. Terra Latinoamericana 24 (4), 529-539.

Pérez-Vargas J., García-Esquivel J.G. y Esparza-García F. (2002). Papel ecológico de la flora rizosférica en la fitorremediación. Avance y Perspectiva 21, 297-300.

Pérez-Silva R.M., Camacho-Pozo M.I., Gómez-Montes de Oca M.J., Ávalos R.A. y Cantero M.D. (2008). Aislamiento y selección de una cepa bacteriana degradadora de hidrocarburos a partir de suelos contaminados con petróleo. Revista CENIC Ciencias Biológicas 39 (1), 44-51.

Richards L.A. (1980). Diagnóstico y rehabilitación de suelos salinos y sódicos. Número 60 del Manual del Departamento de Agricultura de los Estados Unidos. Ed. Limusa, México, 172 pp.

Riojas-González H.H., Gortárez-Moroyoqui P., MondacaFernández I., Balderas-Cortes J.J. y Torres-Bustillos L.G. (2010). Evaluación de la biorremediación aplicando mezclas de surfactante-solvente en suelo contaminado con diesel. Revista Latinoamericana de Recursos Naturales 6 (2), 100-109.

Rivera-Cruz M.C. y Trujillo-Narcia A. (2004). Estudio de toxicidad vegetal en suelos con petróleos nuevo e intemperizado. Interciencia 29 (7), 370-376.

SEMARNAT (2012). Norma Oficial Mexicana NOM138-SEMARNAT/SSA1-2012. Límites máximos permisibles de hidrocarburos en suelos y lineamientos para el muestreo en la caracterización y especificaciones para la remediación. Secretaría de Medio Ambiente y Recursos Naturales. Diario Oficial de la Federación, 10 de septiembre de 2013.

Thompson O.A., Wolf D.C., Mattice J.D. y Thomas G.J. (2008). Influence of nitrogen addition and plant root parameters on phytoremediation of pyrene-contaminated soil. Water Air Soil Poll. 189 (1-4), 37-47.

DOI: $10.1007 / \mathrm{s} 11270-007-9552-4$

USEPA (1998). Method 9071B. n-Hexane extractable material (HEM) for sludge, sediment and soil samples. Método 9071B. United States Enviromental Protection Agency. Manual SW-846. Washington DC, 78 pp.

Vásquez M.C., Guerrero-Figueroa J.T. y Quintero A.P. (2010). Biorremediación de lodos contaminados con aceites lubricantes usados. Revista Colombiana de Biotecnología 12 (1), 141-157.

Velasco J.A. y Volke-Sepúlveda T.L. (2003). El composteo: una alternativa tecnológica para la biorremediación de suelos en México. Secretaría de Medio Ambiente y Recursos Naturales. Gaceta Ecológica 66, 41-53. 
Volke-Sepúlveda T.L. y Velasco J. A. (2002). Tecnologías de remediación para suelos contaminados. Secretaría de Medio Ambiente y Recursos Naturales, Instituto Nacional de Ecología, México, 64 pp.
Walkley A. 1947. A critical examination of a rapid method for determining carbon in soils. Effect of variation in digestion condition and inorganic soil constituents. Soil Sci. 63 (4), 251-264. 